\title{
Infection Control Practices in A University Blood Bank,
}

\section{Alexandria, Egypt}

\author{
Nagwa Y. Abou El Enein *, Abdel Hamid M. El Sherif **
}

\begin{abstract}
Background: The adoption and implementation of sound measures for the control and prevention of infection in blood banks is as important as it is in other clinical departments in the health care organizations. Objectives: assessment of the infection control practices in Alexandria University Blood Bank (AUBB) and identification of annual seroprevalence of viral hepatitis among blood donors in AUBB in the last 10 years. Methods: Cross sectional descriptive study was conducted at AUBB. The sample included 10 physicians, 27 technicians and 18 nurses. Based on the average daily attendance of blood donors, each physician was observed while examining 30 patients. Each nurse was observed while bleeding 30 patients. Each technician was observed while taking samples from 30 patients while each of the technicians working inside the laboratories was observed for 30 occasions. Observation was done by using especially designed checklists. All the blood bank staff under study was interviewed by using specially designed structured questionnaire. Review of the blood bank registers was done to identify annual seroprevalence of viral hepatitis among blood donors in AUBB in the last 10 years Results: The AUCBB was found to be deficient of many resources required for proper implementation of infection control practices. The majority of health care worker in the blood bank including physicians, technicians and nurses were not trained on infection control procedures. Only $5.5 \%$ of nurses was trained. Half percent $(50 \%)$ of the physicians, $39 \%$ of the nurses and $66.6 \%$ of technicians washed their hands before starting work but, none of them washed hands between donors. All technicians, $80 \%$ of nurses and $90 \%$ of the physicians wore gloves. There are no policy and procedures for occupational hazards exposure to blood and body fluids or to sharp injuries although there is high incidence of needle stick injuries specially among nurses (94.4\%). The vaccination coverage to HBV vaccine is poor especially among nurses. Regarding, the frequency of positive results to Transfusion Transmissible Infections (TTIs) as hepatitis $B$ virus (HBV), hepatitis $C$ virus (HCV), and human immunodeficiency virus (HIV) among blood donors in AUBB in the last 10 years, the average prevalence of HBS Ag positive cases among blood donors was $1.46 \%$ and the average HCV positive is $4.62 \%$. HIV prevalence was 5 per 100,000 . It is observed that the trend is decreasing from the year 2000 to the year 2009. Conclusion and Recommendations: Development of policy and procedure manual for infection control in AUBB with supply of resources such as equipment and materials needed for appropriate implementation of infection control guidelines. Education and training of all Health care workers in blood bank about infection control procedures is recommended. Also, HBV Vaccination of all staff who are working in blood bank and exposed to infection should be mandatory.
\end{abstract}

Keywords: Blood bank - Infection control - Vaccination.

\footnotetext{
* Health Administration and Behavioral Sciences Department, High Institute of Public Health, Alexandria University, Egypt.

${ }^{* *}$. Director of the Main Univerisity Blood Bank.
} 


\section{INTRODUCTION}

Infection control refers to policies and procedures designed to provide a safe, sanitary, and comfortable environment for patients, health care workers and visitors in hospitals and health care facilities and minimize the risk of spreading infections among them. ${ }^{(1)} \quad$ The adoption and implementation of sound measures for the control and prevention of infection in blood banks is as important as in other clinical departments in the health care organizations. (2) Non adherence to infection control guidelines results in increased incidence of bacterial contamination of blood units which can have fatal consequences for the recipients of the transfusion. (3)

Blood and body fluid exposures are the most common safety problems in health care workers. ${ }^{(4)}$ Health staffs working in blood banks and transfusion services are at risk of exposure to pathogenic organisms in blood in a number of ways. (1) The major concern after occupational exposure is the possible transmission of blood-borne pathogens. Transmission of more than 20 different pathogens by needlestick and sharps injuries has been reported. Among these, hepatitis B virus (HBV), hepatitis C virus (HCV), and human immunodeficiency virus (HIV) are the most important. Infection by these viruses can lead to serious and even fatal illnesses, constituting major health care problems for health care workers. $^{(4)}$

The risk of $\mathrm{HCV}$ transmission has been found to vary widely between studies. The Center for disease control and prevention (CDC) review of all available data found that on average, the risk was $1.8 \%$ (including patients with negative and positive viraemia). While the risk of HIV transmission after needle stick injury with HIV-contaminated blood is thought to be $0.3 \%$. ${ }^{(5)}$ A study was conducted to explore the frequency of exposure to needle stick 
injuries and hepatitis B vaccination among health care workers (HCW) in Egypt. The study revealed that $69.4 \%$ of interviewed health care workers reported at least one needle stick injury in their lifetime. HBV vaccination coverage was $38.1 \%$ among doctors, $8.8 \%$ among nurses and $5.4 \%$ among laboratory technicians. ${ }^{(6)}$

There is a decline in occupational HBV due largely to the widespread immunization of healthcare personnel. Although universal precautions also help in reducing blood exposures and HBV infections in healthcare personnel. (7) Hepatitis $B$ is one of the diseases for which immunization of HCW is strongly recommended by CDC ${ }^{(8)}$.There is no clear policy that requires mandatory vaccination for health care workers in Egypt $^{(6)}$.

Owing to the importance of adherence to infection control guidelines in blood bank and lack of data about degree of compliance of blood bank managers and personnel to these guidelines, this study was conducted for assessment of this important issue. The study aimed for assessment of the infection control practices in Alexandria University Blood Bank (AUBB) in terms of structure required for standard infection control practices and adherence of physicians, nurses and technicians to infection control guidelines in relation to hand hygiene; wearing gloves; disposal of sharps; laboratory rules and safety precautions. Also, the study aimed to review of the blood bank registers to identify annual seroprevalence of viral hepatitis among blood donors in AUBB in the last 10 years and to identify types of donors.

\section{MATERIAL AND METHODS}

\section{Study setting}

The study was conducted at Alexandria University Blood Bank which is one of the two main governmental blood banks in Alexandria. It supplies blood components to all health care facilities in Alexandria and surrounding governorates. AUBB is a main blood bank in 
which most of blood bank activities are present including blood donation, screening, component preparation, blood grouping and compatibility testing. There are no therapeutic transfusion services. It is a separate department inside Alexandria University Hospitals and is not shared by laboratory or other department. Date collection took place between January till March 2010.

\section{Study design}

Cross sectional descriptive study.

\section{Sampling design and Sample size}

A total of 64 blood bank staff are working in AUBB, they are 13 physicians, 31 technicians and 20nurses. The sample included all the blood bank staff of the three categories who involved in the technical work during the period of the study with exclusion of those who were involved in managerial work. The sample size was 10 physicians, 27 technicians and 18 nurses. i.e. the total was 55 blood bank staff. Based on the average daily attendance of blood donors, each doctor was observed while examining 30 patients. Each technician was observed while taking samples from 30 patients. Each nurse was observed while bleeding 30 patients. Each of the technicians working inside the laboratories was observed for 30 occasions. Observation schedule was planned according to the work schedule of the blood bank (the available staff in the shift). The observations were carried out in both morning shift ( $8 \mathrm{am}-2 \mathrm{pm})$ and afternoon shift (2 pm - 8 pm) equally. In AUBB there is no blood collection from donors in the night shift.

\section{Data collection Techniques and Tools}

The following techniques were used in the study: Observation, interview and retrospective record review.

I. Observation:

1) Assessment of the available resources for infection control practices. The researcher used checklist ${ }^{(8)}$ to assess structure of donation area and laboratories of the blood bank. The 
items were checked whether present or lacking.

2) Observation of physicians, nurses and technicians was done by using especially designed checklists. Observation was done to assess adherence of the three categories to infection control guidelines of blood bank in terms of hand hygiene, wearing gloves, disposal of sharps, laboratory rules and safety precautions. The checklists were designed on basis of infection control guidelines which was developed by collaborative efforts of the Egyptian Ministry of Health $(\mathrm{MOH})$, Family Health International (FHI) and the United States Agency for International Development (USAID). (8) The researchers modified the tool to be suitable to the study setting of the present research as it included some parameters which are not applicable in the setting under study.

II. Interview:

1. Interview with blood bank director by using specially designed structured questionnaire $^{(8)}$ to identify different blood bank activities in general and infection control activities in specific (Items of structure that could not be obtained by observation ).

2. Interview with blood bank staff:

All the blood bank staff under study agreed to participate in the study. Interview was organized using specially designed structured questionnaire based on literature review. (8) It included the following: history of training on infection control, awareness about likelihood of being infected with dangerous infections (HBS, HCV, HIV, History of hepatitis B (HBV) vaccination, source of vaccine for vaccinated individuals, previous exposure to needle sick injury in AUBB, reason of exposure to needle stick injury, intervention towards exposure to needle stick injury and reasons of non adherence to wearing gloves among non adherent physicians, technicians and nurses in AUBB. 
III. Retrospective record review:

Review of the blood bank registers was done to identify annual seroprevalence of viral hepatitis among blood donors in AUBB in the last 10 years and to identify types of donors in the last 4 years.( Only records of last four years were available)

Pilot Study

Pilot study was carried out for the questionnaire and included 2 doctors, 4 technicians and 4 nurses. After the pilot study the questionnaire was reviewed and the needed changes were performed. The results of the pilot were included in the study.

\section{Statistical Analysis}

The data entry and analysis was done by using the Statistical Package for Social Science (SPSS) version 13. The data were presented in simple frequency tables. The adherence to guidelines was calculated as ratio of the frequency of correct action performed (actual performance) to the number of infection control procedures that required to be performed correctly (expected performance).

\section{Ethical considerations:}

Anonymity and confidentiality of participants were ensured throughout the study. The purpose of the study was explained and oral consent from the participants was granted before participating in the study.

\section{RESULTS}

Table (1) represents AUBB structure required for standard infection control practices in the blood bank during the study period. Regarding the structure of donation area, this area is used for donation only with separate clean area for preparing bleeding process materials. The table enlightens the non availability of standard operating procedures manual (SOPs), written guidelines on safety and infection control in the blood bank safety, written donor selection criteria, blood donor questionnaire and educational materials, leaflets or posters. There is special register for recording donors. As regards structure 
of laboratories required for standard infection control practices, there are no availability of safety and infection control guidelines or standard operating procedures (sops). There are availability of sink with running water and soap for hand washing.

In both donation area and laboratories, there are available materials for waste disposal as safety boxes for sharps which is appropriately labeled, Container with disinfectant for glassware, container for fluid waste and leak proof waste basket. In the blood bank, there are no availability of documented orientation program for new staff, documented training programs for staff, written guidelines for safety and infection control in the blood bank, written policy for needle stick or sharps injury post exposure procedures, records for documentation of such events (records of occupational exposures). There are availability of functioning hot air oven, incinerator, cool boxes for transporting blood units and routine maintenance of equipment. From the table it is evident that waste from mobile sessions is returned to blood bank to be disposed with biohazardous waste. No cultures are done for blood units to detect bacterial contamination.

Table (2) demonstrate the distribution of blood bank staff according to history of training on infection control, awareness about likelihood of becoming infected with dangerous infections, previous exposure to needle stick injury and history of vaccination to $B$ virus. Only 3 nurses constituting $16.7 \%$ of the total number of working nurses were trained on infection control procedures. While none of the physicians nor were technicians included in any training program. The percentage of trained staff among total number of working staff was $5.5 \%$. All the Blood bank staff who shared in the questionnaire (100\%) acknowledged their awareness of the likelihood of becoming infected with 
dangerous infections through their contact with blood. The total number of vaccinated staff is $29(52.7 \%)$. Seven out of ten physicians $(70 \%)$ received the vaccine. On the other hand, only 6 nurses out of 18 (33.3\%) and 16 technician out of 27 (59.3 $\%)$ received the vaccine. The vaccine was afforded by the hospital (AUBB) to 18 out of the total 29 vaccinated individuals (62.1\%) while the remaining $37.9 \%$ obtained the vaccine from external sources. For all vaccinated nurses (100\%) and $62.5 \%$ of vaccinated technicians, the vaccine was afforded by the hospital. Whereas $28.2 \%$ of physicians were vaccinated in the hospital, the remaining $71.4 \%$ got the vaccine from outside on their own. Regarding previous exposure to needle stick injury, there are no records for such incidents as we mentioned before so this data is extracted from the interview questionnaire with health care workers. The previously injured workers constitute $50.9 \%$ of all questioned staff. Needle stick injury is a very common

incident among nurses. Seventeen nurses out of 18 nurses $(94.4 \%)$ reported that they were injured by sharps. The incidence was $30 \%$ among physicians and $30.4 \%$ among technicians. The main cause for injury among nurses (100\%) was during filling the sampling tubes after blood collection. For physicians and technicians, the incident occurred during lab procedures. All injured staff $(100 \%)$ stated that nothing was done to them after the injury as there is no policy or procedures for such events.

Table (3) demonstrates adherence of physicians and nurses to infection control guidelines throughout the study period. Regarding the adherence of physicians to infection control guidelines during examination of blood donors, the physicians washed their hands before starting the examination of $1.7 \%$ of donors but none of them (0\%) washed their hands between donors. Wearing gloves while examining donors was done in the 
majority (80\%) but all of them used the same glove for all donors.

As regards adherence of nurses to infection control guideline while bleeding donors, the table shows that in about 1.3 $\%$ of donors the nurses wash their hands before starting the work but none of them ( 0 $\%$ ) wash hands between donors. In $90 \%$ of observations they wore gloves during contact with donors but the rate of changing the gloves was $18 \%$. They change of the gloves occurred if it becomes soiled which is usually happens during filling of the sample tubes. Appropriate disinfection of skin before venipuncture (in circular direction from inside to outside several times) was seen only in $55 \%$ of occasions. A new bag was used for each venipuncture. All the nurses (100\%) filled the sample tubes with needle bared. After sampling, the needles were appropriately disposed in hard leak proof container.

Concerning adherence of technicians to infection control guidelines when taking blood samples from blood donors for hemoglobin test, in $66.6 \%$ of occasions, the technicians washed their hands before starting the work (at the beginning of the day) but none of them (0\%) washed his hands between donors. All the technicians who were included in the study wore gloves during work but they changed the gloves only if they soiled with blood or looks dirty. Rate of changing the gloves among technicians was $5.6 \%$.

Table (4) shows the adherence of technicians to infection control guidelines inside laboratories throughout the study period. They wore gloves during work in $79.8 \%$ of observations while $87.4 \%$ of them did not wear gloves outside work place. In Serology lab and Blood component separation lab, the working surface is always cleaned with disinfectant before starting work and after finishing work. On the other hand, only in $33.3 \%$ of observations, the technicians assigned in blood grouping/cross matching laboratory, 
cleaned the working surface before starting laboratory procedures. Regarding cleaning working surface after the procedure, all of technicians instructed the housekeepers to clean at the end of duty. Mouth pipetting was not done in the three laboratories. Visible blood contaminated materials as blood soiled pieces of cotton were always seen (100 \%) in blood grouping/cross matching laboratory but were not observed in serology lab or blood component separation lab. The technicians were adherent in $36.9 \%$ of situations that needed adherence to infection control guidelines and rules which prohibit eating or drinking inside the laboratory. All technicians were keen to wash their hands before leaving the laboratory working area (100\%).

Table (5) demonstrates the barriers of adherence to wearing the gloves among non adherent physicians, technicians and nurses in AUBB. Loss of sensation while working was the commonest reported cause of non-adherence (75\%); followed by allergy to gloves (56.3\%); presence of workload (37.5\%) and non availability of suitable size (37.5\%).

Table (6) illustrates the distribution of blood donation types in AUBB during the last 4 years prior to our study. Family replacement donors constituted the mainstream (average within the last 4 years is $80.9 \%$ ). Directed donation was very few $(0.02 \%)$. The percentage of voluntary nonremunerated donors was $12.9 \%$ in 2006 and increased to $25.7 \%$ in 2009.

Figure (1) represents the frequency of positive results to TTIs among blood donors in AUBB in the last 10 years. The average prevalence of HBS $\mathrm{Ag}$ positive cases among blood donors was $1.46 \%$. The average HCV positive is $4.62 \%$. HIV prevalence was 5 per 100,000 . It is observed that the trend is decreasing from the year 2000 to the year 2009 .

\section{DISCUSSION}

Standards of Egyptian accreditation 
program necessitate the presence of phasing out of family/replacement donation approved policies and procedures on infection control in all hospital departments that should include: selection and uses of antiseptics and disinfectants; hand washing techniques; all cleaning activities; standard precautions; disposal of sharps and hazardous materials in addition to other infection control activities specific to each department. A formal orientation program for all employees must be present and infection control is an essential part of it (9). There is an infection control unit in Alexandria University Hospital including representatives from many departments like surgery, obstetric, nursing, laboratory, housekeeping and central supply but there is no representative from blood bank.

WHO recommends an integrated strategy for the provision of safe blood. One of its elements is collection of blood from voluntary non-remunerated blood donors (VNRBD) to minimize the risk of infections that can be transmitted through blood, the and the elimination of paid donation $(10,11,12)$. AUBB is on the road for achievement of this as the percentage of voluntary nonremunerated donors (VNRBD) increased from $13 \%$ in 2006 to $25.7 \%$ in 2009 and paid donors have been eliminated (Table 6). Most European countries have reached $100 \%$ VNRBD. In Cambodia VNRBD levels remain stable at $25 \%$ of total with ongoing reliance on family replacement donation. In Indonesia, $82 \%$ are voluntary donors while in Pakistan only $15 \%$ are from VNRBD. In the Philippines overall rates of VNRBD have reached 55\%. In June 2009, Melbourne, Australia, a global consultation held by WHO announced a declaration aiming to achieve $100 \%$ VNRBD by all countries by $2020^{(12)}$. In Egypt conversion to VNRBD may be achievable but will not happen in a vacuum. It requires a well organized and resourced blood system. Government support for the transition is essential. Culture and attitudes will also be 
barriers to change. Pre-requisites include health authority commitment, a national program, community mobilization and support from the media, NGOs and international organizations. Lessons can be learned from countries which have successfully managed the transition.

There is no clear policy requiring mandatory vaccination of Hepatitis B Virus for HCWs in Egypt ${ }^{(13)}$. Immunization of HCW against hepatitis $B$ is strongly recommended by $\mathrm{CDC}, \mathrm{WHO}$ as well as Egyptian infection control guidelines $(13,14)$. Only $33.3 \%$ of nurses in AUBB were vaccinated. All of them got the vaccine from the facility (governmental) when it was given in a compulsory basis about 15 years ago. The vaccine is not afforded nowadays. All the non vaccinated nurses mentioned that they were not working in AUBB at that time and the price of the vaccine is relatively high, they cannot afford it on their own. So, they were not vaccinated. Higher percentage of technicians were vaccinated compared to other categories (59.3\%) and this is due the fact that they were included in a vaccination program held by the hospital laboratory department about 6 years ago for all laboratory technicians in the hospital. As regards physicians, $71.4 \%$ of them were vaccinated on their own because they recognize the importance of being vaccinated and no financial constrains present. Talaat et al., (2003) found HBV vaccination coverage $38.1 \%$, $8.8 \%$, and $5.4 \%$ among doctors, nurses and laboratory technicians respectively. ${ }^{(6)}$ In the current study, vaccination coverage was $70 \%, 33.3 \%$ and $59.3 \%$ among doctors, nurses and technicians respectively. AUBB must develop vaccination program to vaccinate all unvaccinated workers specially nurses because they are highly exposed to needle stick injuries according to the study (94.4\% of nurses were injured) (table 2).

There is no written policy for needle stick or sharps injury post exposure 
procedures and no records of such events in AUBB in spite of the high incidence especially among nurses (table 2) and the mandatory requirement by Egyptian accreditation standards to develop this policy and inform the employee about it as it states: Education and training must be provided and documented for occupational health hazards and safety procedures. Over ninety percent of nurses were injured during filling the sampling tubes after blood collection because the needle is uncovered. Although all blood bags are supplied with a secure plastic cap which can be pulled securely to cover the needle. This was not done in AUBB because if the needle is covered it would be very difficult to fill the sample tubes and blood would pour outside. The plastic cap is designed to be used with vacutainer tubes which can be pushed inside it and no blood would gush while the needle is still inside and no chance to injure the nurse. This type of tubes is not available in AUBB due to its higher cost than ordinary plastic tubes although it is widely used in laboratories in the hospital. It was observed that all the nurses and technicians disposed sharps and needles appropriately (100\%) as the puncture resistant required container which was always available. (table 3)

Appropriate hand hygiene practice is crucial to the safety of blood and blood products at all stages in the transfusion chain during which the donated blood units are handled. The microbial contamination of blood or blood products may occur at the time of blood collection or during the processing into blood products, labeling, storage and transportation, or during administration of blood at the patient bedside ${ }^{(2)}$. This can have fatal consequences for the recipients of the transfusion. Serious consequences of microbial contamination can be avoided by giving particular attention to the hand hygiene of the donor care staff at the time of blood collection and by thorough 
cleansing of the venepuncture site on the donor arm. None of the physicians, nurses or technicians wash their hands between donors (tables 3). Education of staff about the importance and appropriate methods of hand hygiene should be stressed on.

Changing gloves in between donors is rarely done by most of blood bank workers (tables 3). Importance of this issue should be stressed on in addition to providing sufficient amount of gloves with different sizes to hold back non-availability as reason of nonadhrence to this standard (table 5).

Most of the AUBB HCWs showed poor adherence to infection control standard guidelines (table 3). Lack of training was the noticeable cause in addition to absence of guidance from the supervisors and nonexistence of posters or any other form of education about infection control. Regarding laboratory technicians, they were adherent to measures which can be a form of general cleaning but safety rules and regulations as regards infection control were ignored. The most obvious non adherence item was the usual eating and drinking inside the laboratory. Only on 36.9 $\%$ of occasions observed in all the three laboratories, no food or drink was seen (table 4). The consistent finding of visible blood contaminated materials in blood grouping and cross matching laboratory is the second most dreadful observation of non adherence to infection control measures.

An important quality control measure is to randomly select blood units, platelets concentrates and plasma to be cultured for detection bacterial contamination. This is needed for assessing the situation of infection control in blood bank, for benchmarking with other blood banks, evaluation of infection control interventions and early tracing of trends if the rate of contaminated units exceeds acceptable standard levels. ${ }^{(15)}$ Unfortunately this is not performed in AUBB (table 1). 
Blood screening activities for transfusion transmitted infections done in AUBB include hepatitis B virus, hepatitis C virus, HIV and syphilis. They are done for all donors. The sero-prevalence of hepatitis B and hepatitis C was monitored and compared to the findings of another study that was done in Al Mansoura on blood donors ${ }^{(16)}$. The mean of HBV prevalence in AUBB blood donors was $1.46 \%$ while it was $1.24 \%$ in the mentioned study ( $p=$ 0.0027). The prevalence of HCV in AUBB blood donors was $4.62 \%$ which is significantly lower than that of Al Mansoura study $(11.63 \%)(p=0.0089)$. This may be due to the fact that their blood donors are from rural areas in which the frequency of hepatitis in higher than urban areas and these results reflect to some extent the total population prevalence.

\section{CONCLUSION AND RECOMMENDATIONS}

The AUCBB was found to be deficient of many resources required for proper implementation of infection control practices. There were no policies or procedures in donation area as well as the laboratories. The majority of $\mathrm{HCW}$ in the blood bank including physicians, technicians and nurses were not trained on infection control procedures. Only $5.5 \%$ were trained but this training was not documented. No educational materials or posters were seen in any area in the blood bank. As regards hand hygiene $50 \%$ of the doctors, $39 \%$ of the nurses and $66.6 \%$ of technicians wash their hands before starting work, but none of them wash hands between donors. On the other hand, the adherence to wearing gloves is good. There are no policy and procedures for occupational hazards exposure to blood and body fluids or to sharp injuries although there is high incidence of needle stick injuries specially among nurses (94.4\%).

The vaccination coverage to $\mathrm{HBV}$ vaccine is poor especially among nurses. The seroprevalence of $\mathrm{HBV}$ and $\mathrm{HCV}$ among blood donors in AUBB is relatively 
low compared to other Egyptian guidelines. is recommended. HBV populations but the percent of VNRBD is Vaccination of all HCWs who are working in remote from the recommended by WHO for blood bank and exposed to infection should the production of safe blood. be mandatory. Evaluating the benefits and

Development of policy and procedure cost effectiveness of the purchase of manual for infection control in AUBB with vacutainer tubes to avoid the injury of nurse supply of resources such as equipment and during sampling from blood bags is needed. materials needed for appropriate Cooperation with non governmental implementation of infection control organizations (NGOs), educational guidelines. Education and training of all institutions, political parties, media and health care workers (HCWs) in blood bank other allied social gathering to build about infection control procedures with strategies in order to raise the number of continuous observation of staff for the voluntary non-remunerated blood donors implementation of infection control (VNRBD). 
Table (1): Assessment of AUBB Structure Required for Standard Infection Control Practices in the Blood Bank During the Study Period.

\begin{tabular}{|c|c|c|}
\hline Structure & $\begin{array}{c}\text { Present } \\
\text { (Available) }\end{array}$ & $\begin{array}{c}\text { Lacking } \\
\text { (Not available) }\end{array}$ \\
\hline \multicolumn{3}{|l|}{ Donation area } \\
\hline The area used for donation of blood only & $\sqrt{ }$ & \\
\hline Educational materials, leaflets or posters & & $\sqrt{ }$ \\
\hline Guidelines or Standard Operating Procedures Manual & & $\sqrt{ }$ \\
\hline A separate clean area for preparing bleeding process materials & $\sqrt{ }$ & \\
\hline Written guidelines on safety and infection control in the blood bank & & $\sqrt{ }$ \\
\hline Written donor selection criteria & & $\sqrt{ }$ \\
\hline Blood donor questionnaire & & $\sqrt{ }$ \\
\hline Register for recording of donor. & $\sqrt{ }$ & \\
\hline $\begin{array}{l}\text { Available materials for waste disposal: } \\
\text { - Safety box for sharps and appropriately labeled. } \\
\text { - Container with disinfectant for glassware } \\
\text { - Container for fluid waste } \\
\text { - Leak proof waste basket }\end{array}$ & $\begin{array}{l}\sqrt{ } \\
\sqrt{ } \\
\sqrt{ } \\
\sqrt{ }\end{array}$ & \\
\hline \multicolumn{3}{|l|}{$\begin{array}{l}\text { Laboratories } \\
\text { (Blood grouping \& Cross-matching, component Preparation } \\
\text { and serology) }\end{array}$} \\
\hline Safety and Infection Control guidelines & & $\sqrt{ }$ \\
\hline Standard operating procedures (SOPs) & & $\sqrt{ }$ \\
\hline Sink with running water & $\sqrt{ }$ & \\
\hline Soap for hand washing & $\sqrt{ }$ & \\
\hline $\begin{array}{l}\text { Available materials for waste disposal : } \\
\text { a- Safety box for sharps } \\
\text { b- Container for fluid waste } \\
\text { c- Waste basket for non sharps biohazards } \\
\text { d- General waste basket }\end{array}$ & $\sqrt{ }$ & \\
\hline \multicolumn{3}{|l|}{ Miscellaneous items } \\
\hline Documented orientation programs for new staff & & $\sqrt{ }$ \\
\hline Documented training programs for staff & & $\sqrt{ }$ \\
\hline Records of occupational exposures & & $\sqrt{ }$ \\
\hline Written policy for post-exposure procedures & & $\sqrt{ }$ \\
\hline Written guidelines on safety and infection control in the blood bank & & $\sqrt{ }$ \\
\hline $\begin{array}{l}\text { waste from mobile sessions is returned to blood bank to be } \\
\text { disposed with biohazardous waste }\end{array}$ & $\sqrt{ }$ & \\
\hline Functioning hot air oven in the blood bank & $\sqrt{ }$ & \\
\hline Functioning incinerator in the facility & $\sqrt{ }$ & \\
\hline Cool boxes for transporting blood units & $\sqrt{ }$ & \\
\hline Routine maintenance of equipment & $\sqrt{ }$ & \\
\hline Units randomly cultured for bacterial contamination & & $\sqrt{ }$ \\
\hline
\end{tabular}


Table (2): Distribution of Blood Bank Staff According to History of Training on Infection Control, Awareness About Likelihood of Becoming Infected With Dangerous Infections, Needle Stick Injury in AUBB (previous exposure, reason and intervention) and History of Vaccination to Hepatitis B Virus (HBV).

\begin{tabular}{|c|c|c|c|c|c|c|c|c|}
\hline \multirow{3}{*}{ Items } & \multicolumn{8}{|c|}{ Job Category } \\
\hline & \multicolumn{2}{|c|}{$\begin{array}{l}\text { Physicians } \\
(n=10)\end{array}$} & \multicolumn{2}{|c|}{$\begin{array}{c}\text { Technicians } \\
(\mathrm{n}=27)\end{array}$} & \multicolumn{2}{|c|}{$\begin{array}{c}\text { Nurses } \\
(n=18)\end{array}$} & \multicolumn{2}{|c|}{ Total $(n=55)$} \\
\hline & No & $\%$ & No & $\%$ & No & $\%$ & No & $\%$ \\
\hline $\begin{array}{l}\text { History of training on infection control } \\
(n=55) \\
\text { Trained } \\
\text { Not trained }\end{array}$ & $\begin{array}{c}0 \\
10\end{array}$ & $\begin{array}{c}0 \\
100\end{array}$ & $\begin{array}{c}0 \\
27\end{array}$ & $\begin{array}{c}0 \\
100\end{array}$ & $\begin{array}{c}3 \\
15\end{array}$ & $\begin{array}{l}16.7 \\
83.3\end{array}$ & $\begin{array}{c}3 \\
52\end{array}$ & $\begin{array}{c}5.5 \\
94.5\end{array}$ \\
\hline $\begin{array}{l}\text { Awareness about likelihood of being } \\
\text { infected with dangerous infections (HBS, } \\
\text { HCV, HIV) ( } n=55) \\
\text { Yes }\end{array}$ & 10 & 100 & 27 & 100 & 18 & 100 & 55 & 100 \\
\hline $\begin{array}{l}\text { History of hepatitis B (HBV) vaccination } \\
(\mathbf{n}=55) \\
\text { Yes } \\
\text { No }\end{array}$ & $\begin{array}{l}7 \\
3\end{array}$ & $\begin{array}{l}70.0 \\
30.0\end{array}$ & $\begin{array}{l}16 \\
11\end{array}$ & $\begin{array}{l}59.3 \\
40.7\end{array}$ & $\begin{array}{c}6 \\
12\end{array}$ & $\begin{array}{l}33.3 \\
66.7\end{array}$ & $\begin{array}{l}29 \\
26\end{array}$ & $\begin{array}{l}52.7 \\
47.3\end{array}$ \\
\hline $\begin{array}{l}\text { Staff received HBV vaccine from AUBB } \\
(\mathbf{n}=29) \\
\text { Yes } \\
\text { No }\end{array}$ & $\begin{array}{l}2 \\
5\end{array}$ & $\begin{array}{l}28.6 \\
71.4\end{array}$ & $\begin{array}{c}10 \\
6\end{array}$ & $\begin{array}{l}62.5 \\
37.5\end{array}$ & $\begin{array}{l}6 \\
0\end{array}$ & $\begin{array}{c}100 \\
0\end{array}$ & $\begin{array}{l}18 \\
11\end{array}$ & $\begin{array}{l}62.1 \\
37.9\end{array}$ \\
\hline $\begin{array}{l}\text { previous exposure to needle stick injury } \\
\text { in AUBB }(n=55) \\
\text { Yes }\end{array}$ & 3 & 30.0 & 8 & 30.0 & 17 & 94.4 & 28 & 50.9 \\
\hline $\begin{array}{l}\text { Reason of exposure to needle stick } \\
\text { injury }(\mathbf{n}=\mathbf{2 8}) \\
\text {-During lab procedures } \\
\text {-During filling the sampling tubes after blood } \\
\text { collection }\end{array}$ & $\begin{array}{l}3 \\
-\end{array}$ & $\begin{array}{c}100 \\
-\end{array}$ & $\begin{array}{l}3 \\
-\end{array}$ & $\begin{array}{c}100 \\
-\end{array}$ & - & 100 & - & 100 \\
\hline $\begin{array}{l}\text { Intervention towards exposure to needle } \\
\text { stick injury }(\mathbf{n}=28) \\
\text { No }\end{array}$ & 3 & 100 & 3 & 100 & 17 & 100 & 28 & 100 \\
\hline
\end{tabular}


Table 3: Adherence of Physicians and Nurses to Infection Control Guidelines in AUBB Throughout The Study Period

\begin{tabular}{|c|c|c|}
\hline Infection control procedure & $\begin{array}{l}\text { Frequency of correct } \\
\text { action performed }\end{array}$ & $\%$ \\
\hline \multicolumn{3}{|l|}{$\begin{array}{l}\text { Adherence of physicians to infection control guideline during } \\
\text { examination of donors }\end{array}$} \\
\hline Washing hands before starting examination of donors $(n=300)$ & 5 & 1.7 \\
\hline $\begin{array}{l}\text { Washing hands between donors } \\
(n=300)\end{array}$ & 0 & 0 \\
\hline Wearing gloves $(n=300)$ & 240 & 80 \\
\hline Changing gloves between donor $(n=300)$ & 0 & 0 \\
\hline \multicolumn{3}{|l|}{$\begin{array}{l}\text { Adherence of nurses to infection control guidelines while } \\
\text { bleeding donors }\end{array}$} \\
\hline Washing hands before starting work $(n=540)$ & 7 & 1.3 \\
\hline Washing hands between donors $(n=540)$ & 0 & 0 \\
\hline Wearing gloves $(n=540)$ & 485 & 90 \\
\hline Changing gloves between donor $(n=540)$ & 97 & 18 \\
\hline The skin disinfection done appropriately before venipncture $(n=540)$ & 298 & 55 \\
\hline Using a new bag for each venipuncure $(n=540)$ & 540 & 100 \\
\hline Filling sample tubes with the needle bared $(n-540)$ & 0 & 0 \\
\hline Covering venipuncure site with bandage after donation $(n=540)$ & 540 & 100 \\
\hline Sharps and needles appropriately disposed $(n=540)$ & 540 & 100 \\
\hline \multicolumn{3}{|l|}{$\begin{array}{l}\text { Adherence of technicians to infection control guideline as } \\
\text { regards hemoglobin testing for donors }\end{array}$} \\
\hline Washing hands before starting * $(n=810)$ & 540 & 66.6 \\
\hline Washing hands between donors $(n=810)$ & 0 & 0 \\
\hline Wearing gloves $(n=810)$ & 810 & 100 \\
\hline Changing gloves between donors $(\mathrm{n}=810)$ & 45 & 5.6 \\
\hline Reuse lancet for more than one donor $(n=810)$ & 0 & 0 \\
\hline
\end{tabular}

* They wash their hand at the beginning of the day. 
Bull High Inst Public Health Vol. 40 No. 2 [2010]

\begin{tabular}{|c|c|c|c|c|c|c|c|c|c|c|}
\hline $\bar{t}_{0}$ & ○ீ & $\stackrel{\infty}{\infty}$ & $\underset{\infty}{\stackrel{d}{d}}$ & $\frac{9}{i n}$ & $\overline{\infty o}$ & 움 & $\stackrel{m}{\text { ల్ల }}$ & $\begin{array}{l}\stackrel{9}{0} \\
\stackrel{\rho}{0}\end{array}$ & 우 & 움 \\
\hline 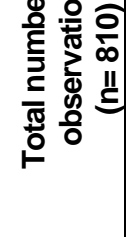 & 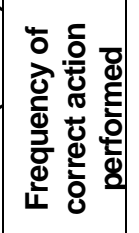 & $\stackrel{0}{0}$ & $\stackrel{\infty}{R}$ & ঙ্ণ & ষ্ল & $\frac{0}{\infty}$ & $\stackrel{?}{\text { ล }}$ & 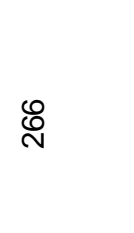 & $\frac{\circ}{\infty}$ & $\frac{\circ}{\infty}$ \\
\hline ه & $\circ^{\circ}$ & 犬ें & $\hat{\infty}$ & $\stackrel{m}{\text { ల్ల }}$ & 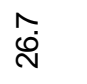 & 음 & 0 & $\overline{\dot{m}}$ & 음 & 음 \\
\hline 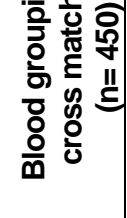 & 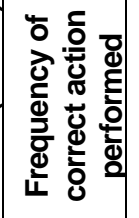 & $\begin{array}{l}\stackrel{0}{\forall} \\
\stackrel{f}{ }\end{array}$ & 导 & 모 & $\stackrel{\text { N}}{\sim}$ & 号 & 0 & 움 & 㝵 & 号 \\
\hline & $\circ$ & $\underset{\stackrel{N}{N}}{\stackrel{N}{n}}$ & 음 & 웅 & 음 & 음 & 웅 & $\stackrel{m}{\mathscr{P}}$ & 으 & 음 \\
\hline 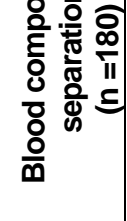 & 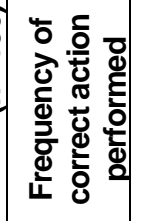 & $\widehat{\vartheta}$ & $\stackrel{\infty}{\mp}$ & 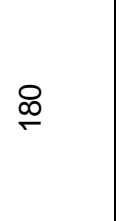 & $\stackrel{\infty}{\oplus}$ & $\frac{0}{\infty}$ & $\stackrel{\infty}{\mp}$ & $\hat{\infty}$ & 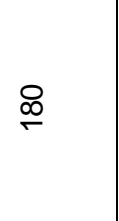 & $\underset{\leftarrow}{\infty}$ \\
\hline & $\circ$ & 曲 & $\hat{\phi}$ & 우 & 웅 & 웅 & 웅 & $\hat{\stackrel{d}{~}}$ & 우 & 웅 \\
\hline 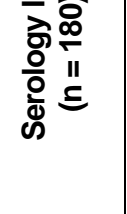 & 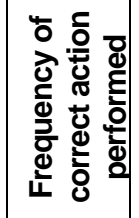 & مٌ & $\stackrel{+}{\stackrel{N}{\sigma}}$ & $\underset{\infty}{\mp}$ & $\nsubseteq$ & $\stackrel{\infty}{\square}$ & $\stackrel{\infty}{\mp}$ & $\stackrel{\infty}{+}$ & $\stackrel{\infty}{\square}$ & 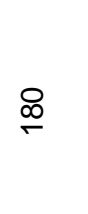 \\
\hline & 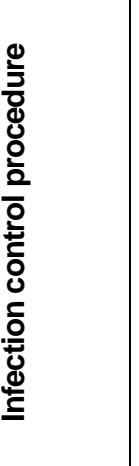 & 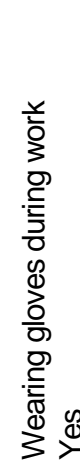 & 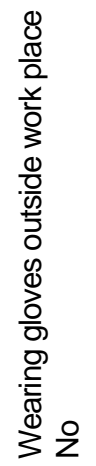 & 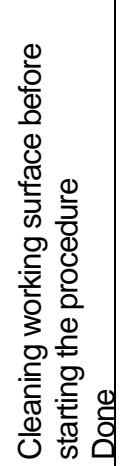 & 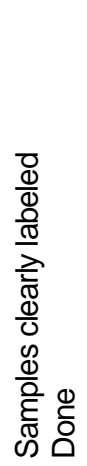 & 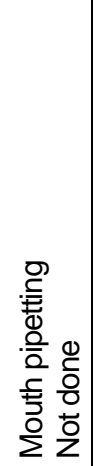 & 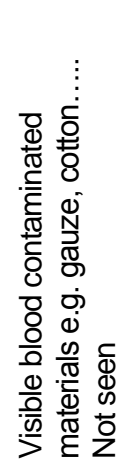 & 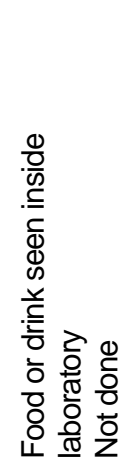 & 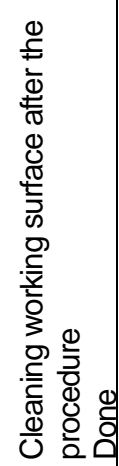 & 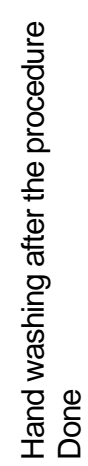 \\
\hline
\end{tabular}


Table (5): Reasons of Non Adherence to Wearing Gloves Among Non adherent Physicians, Technicians and Nurses in AUBB*

\begin{tabular}{|l|c|c|c|c|c|c|c|c|}
\hline \multirow{2}{*}{ Job category } & \multicolumn{2}{|c|}{$\begin{array}{c}\text { Allergic to } \\
\text { gloves }\end{array}$} & $\begin{array}{c}\text { coss of } \\
\text { sensation during } \\
\text { examination }\end{array}$ & $\begin{array}{c}\text { Non availability } \\
\text { of suitable size }\end{array}$ & \multicolumn{2}{c|}{ workload } \\
\cline { 2 - 9 } & No & $\%$ & No & $\%$ & No & $\%$ & No & $\%$ \\
\hline Physicians $(n=2)$ & 1 & 50 & 2 & 100 & 0 & 0 & 1 & 50 \\
\hline Technicians $(n=7)$ & 6 & 85.7 & 5 & 71.4 & 2 & 28.6 & 2 & 28.6 \\
\hline Nurses $(n=7)$ & 2 & 28.6 & 5 & 71.4 & 4 & 57.1 & 3 & 42.9 \\
\hline Total $(n=16)$ & 9 & 56.3 & 12 & 75 & 6 & 37.5 & 6 & 37.5 \\
\hline
\end{tabular}

${ }^{*}$ More than one reason was mentioned

Table (6): Types of Blood donors in Alexandria University Blood Bank in the last 4 years before the study period

\begin{tabular}{|c|c|c|c|c|c|c|c|c|}
\hline \multirow{2}{*}{ Year } & \multicolumn{6}{|c|}{ Types of Blood donors } & \multicolumn{2}{c|}{ Total } \\
\cline { 2 - 9 } & $\begin{array}{c}\text { Voluntary non- } \\
\text { remunerated }\end{array}$ & \multicolumn{2}{|c|}{$\begin{array}{c}\text { Family } \\
\text { replacement }\end{array}$} & \multicolumn{2}{c|}{ Directed } & \multicolumn{2}{c|}{} \\
\cline { 2 - 9 } & No. & $\%$ & No. & $\%$ & No. & $\%$ & No. & $\%$ \\
\hline 2006 & 7198 & 12.9 & 48426 & 87.1 & 0 & 0.000 & 55624 & 100 \\
\hline 2007 & 8925 & 16.4 & 45607 & 83.6 & 8 & 0.015 & 54540 & 100 \\
\hline 2008 & 10696 & 21.2 & 39777 & 78.8 & 17 & 0.034 & 50490 & 100 \\
\hline 2009 & 14558 & 25.7 & 42083 & 74.3 & 19 & 0.034 & 56660 & 100 \\
\hline Total & 41377 & 19.0 & 175893 & 80.9 & 44 & 0.020 & 217314 & 100 \\
\hline
\end{tabular}




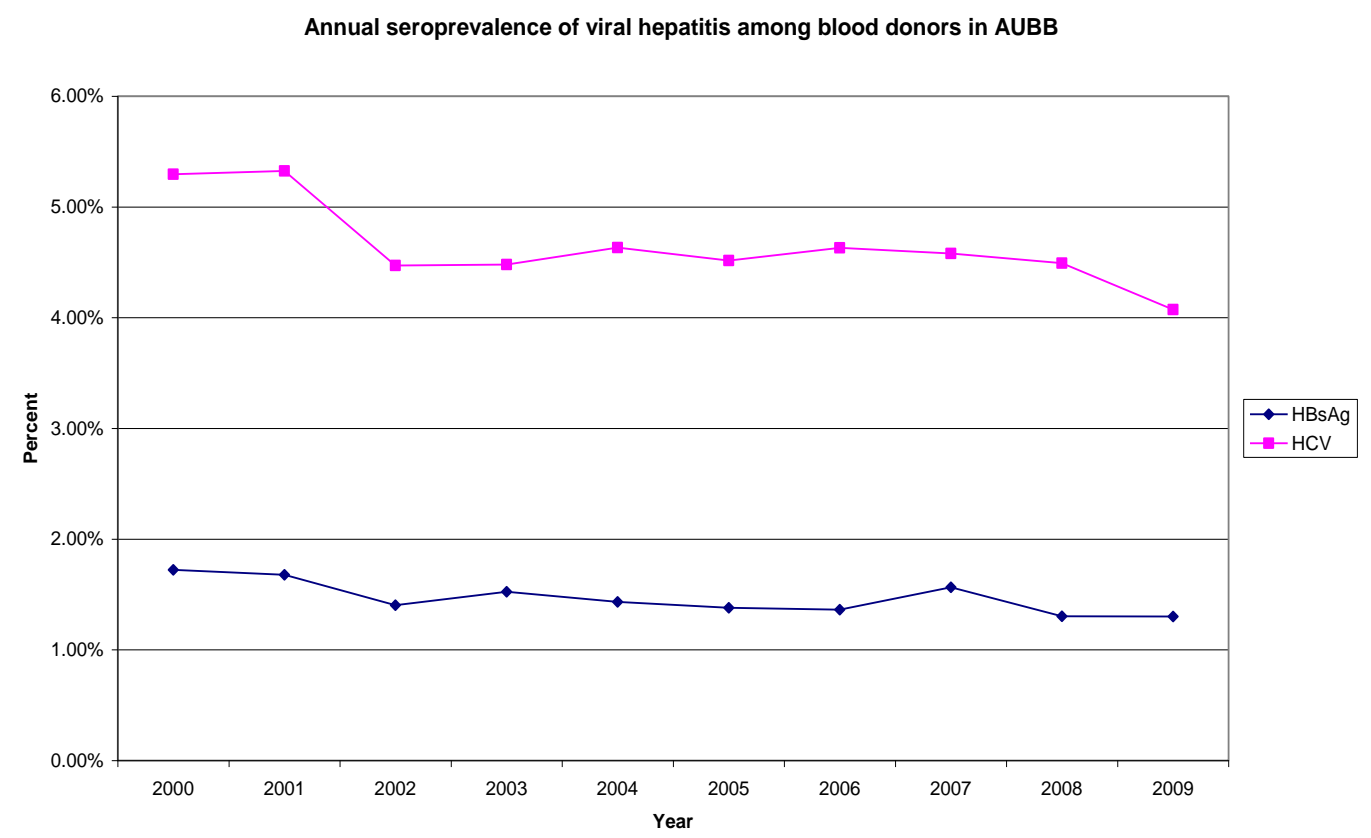

Figure (1) Annual Seroprevalence of Viral Hepatitis Among Blood Donors in AUBB in The Last 10 Years

\section{REFERENCES}

1. Tietjen L, Bossemeyer D, Mclntosh N. Infection Prevention Guidelines for Healthcare Facilities with Limited Resources. JHPIEGO, 2003;18 Available from: http://www.reproline.jhu.edu/english/4 morerh/4ip/IP manual/ipmanual.htm. (accessed 1 March 2010)

2. WHO. World alliance for patient safety, WHO guidelines on hand hygiene in health care, 2005. Available from: http://whqlibdoc.who.int/publications/2 009/9789241597906 eng.pdf. (accessed 1 March 2010)

3. Englbreit CP, Reesink HW, Blajchman MA. Bacterial contamination of blood components. Vox sang. 2000;78:59-67.
4. Kuruuzum Z, Yapar N, Aslan H, Ozbek OA, Cakir N, Yuce A. Risk of infection in health care workers following occupational exposure to a noninfectious or unknown source. AJIC.2008; 36(10): 27-31.

5. Lee R. Occupational transmission of bloodborne diseases to healthcare workers in developing countries: meeting the challenges. Journal of Hospital Infection. 2009;72:285-91.

6. Talaat M, Kandeel A, El-Shoubary W. Occupational exposure to needlestick injuries and hepatitis B vaccination coverage among health care workers in Egypt. Am J Infect Control.2003; 31(8):469-74. 
7. Fahey BJ, Koziol DE, Banks SM, Henderson DK. Frequency of nonparenteral occupational exposure to blood and body fluids before and after universal precautions training. Am J Med. 1991;90:145-53.

8. CDC .Immunization of Health-Care Workers: Recommendations of the Advisory Committee on Immunization Practices (ACIP) and the Hospital Infection Control Practices Advisory Committee (HICPAC). MMWR Morb Mortal Wkly Rep, 1997;46 (RR-18):1-42. Available from: http://www.cdc.gov/mmwr/preview/mmwr html/00050577.htm. (accessed 1 March 2010)

9. FHI, Egyptian MOPH and USAID Infection Control Practices Assessment Tool for Blood Banks.2004 available from: http://www.fhi.org/en/CountryProfiles/E gypt/res infectctrl.htm. (accessed 1 March 2010)

10. $\mathrm{MOH}$. Egyptian accreditation program. July 2007.

11. WHO. Screening donated blood for transfusion-transmissible Infections recommendations.2009. Available from: http://www.who.int/bloodsafety/Screening TTI.pdf. (accessed 1 March 2010)

12. Safe Blood and Blood Products. Introductory Module: Guidelines and Principles for Safe Blood Transfusion
Practice. Geneva, World Health Organization,2002http://www.who.int/bloo dsafety/transfusion services/en/Blood S afety Eng.pdf. (accessed 1 March 2010)

13. WHO. Global Consultation 100\% Voluntary Non-Remunerated Donation of Blood and Blood Components 9-11 June 2009, Melbourne, Australia available from: www.who.int/entity/bloodsafety/Report GlobalConsultation2009onVNRBD.pdf. (accessed 1 March 2010)

14. Stein AD, Makarawo TP, Ahmad MFR. A survey of doctors' and nurses' knowledge, attitudes and compliance with infection control guidelines in Birmingham teaching hospitals. Journal of Hospital Infection. 2003;54:68-73.

15. $\mathrm{MOH}$. Egyptian National guidelines for Infection Control. Available from: http://www.ems.org.eg/esic home/Gui deline part1.htm. (accessed 1 May 2010)

16. American Association of Blood Banks: Guidance on implementation of new bacteria reduction and detection. Standards AABB Bulletin.2004;4(07)

17. Ismail $A M$, Ziada HN, Sheashaa HA, Shehab El-Din AB. Decline of viral hepatitis prevalence among asymptomatic Egyptian blood donors: A glimmer of hope. European Journal of Internal Medicine. 2009; 20:490-3. 